\title{
Clinical Profile of Plasmodium vivax Malaria in Children and Study of Severity Parameters in relation to Mortality: A Tertiary Care Centre Perspective in Mumbai, India
}

\author{
Manju Kumari and Radha Ghildiyal \\ Department of Pediatrics, T. N. Medical College, BYL Nair Hospital, Mumbai, India \\ Correspondence should be addressed to Manju Kumari; manjunot@gmail.com
}

Received 5 July 2014; Revised 14 September 2014; Accepted 20 September 2014; Published 2 November 2014

Academic Editor: Polrat Wilairatana

Copyright (C) 2014 M. Kumari and R. Ghildiyal. This is an open access article distributed under the Creative Commons Attribution License, which permits unrestricted use, distribution, and reproduction in any medium, provided the original work is properly cited.

\begin{abstract}
Background. While research on $P$. vivax is scarce because it is considered benign, it has become evident with implementation of molecular diagnosis that it can also cause multiple organ dysfunction and severe life-threatening disease. Objective. To study clinical presentations and complications of $P$. vivax malaria and mortality correlation to severity parameters as defined by WHO criteria for severe malaria. Materials and methods. This study was conducted in a tertiary care centre in Mumbai. Confirmed $P$. vivax cases were enrolled and studied for their clinical profile, and WHO severity parameters were tested for their frequency and association to mortality. Result. The most common presentation was fever followed by pallor. $26 \%$ of the cases satisfied one or more criteria of WHO severity parameters. 2 cases died; both had pulmonary edema and bleeding. The major predictor of mortality among these predefined severity criteria was pulmonary edema/ARDS. Patients with severe anemia, circulatory collapse, and repeated generalized convulsion had $100 \%$ survival rate. Leukopenia was present in $10 \%$ of the cases. Both cases with mortality had leukopenia. Conclusion. P. vivax monoinfection tends to have severe complications in children. There is a need to review severity criteria for $P$. vivax malaria.
\end{abstract}

\section{Introduction}

Four countries account for more than $80 \%$ of estimated cases of $P$. vivax cases (Ethiopia, India, Indonesia, and Pakistan). India alone contributes $80 \%$ of southeast Asia malaria burden. The risk of severe $P$. vivax disease in residents of endemic areas has been observed to rise with increasing transmission intensity, although the contribution of less access to care and more comorbidity in these settings is not well quantified. As a result of the slower rate of decrease in the incidence of $P$. vivax, many malaria control programs that are moving towards elimination need to give greater attention to the control of $P$. vivax, particularly in countries outside subSaharan Africa. Indeed, P. vivax predominates in countries in the preelimination and elimination phases [1].

P. vivax malaria has long been considered to have a benign course with multiple relapses. The typical complications seen in P. falciparum malaria are not usually found in P. vivax monoinfections. However, during the past few years, the trend in the clinical manifestations of $P$. vivax malaria has been changing [2]. Several isolated studies from India have reported severe complicated cases of $P$. vivax malaria [3].

Although this type of malaria is an enormous burden of disease, research about the disease is scarce probably because of it being considered benign malaria compared to $P$. falciparum malaria. However, with implementation of molecular diagnosis, it has become evident that $P$. vivax monoinfection could also be involved in multiple organ dysfunction and severe life-threatening disease as seen in $P$. falciparum infection $[4,5]$.

\section{Materials and Methods}

2.1. Setting of Study. A prospective hospital-based clinical observational study was done over 2 years in a pediatric ward 
of a tertiary care hospital situated in Mumbai, India. A total of 50 patients under age of 12 years were enrolled in the study.

2.2. Ethical Issues. The institutional ethical committee approved the study.

\subsection{Inclusion Criteria}

(1) Children in age group of below 12 years.

(2) Peripheral smear or rapid malaria antigen test (RMAT) positive for Plasmodium vivax malaria.

(3) Availability of a written informed consent.

\subsection{Exclusion Criteria}

(1) Nonavailability of consent.

(2) Peripheral smear positive for $P$. falciparum or positive for both $P$. falciparum and $P$. vivax.

(3) Patient presenting with fever (malarial parasite negative on peripheral smear and/or RMAT negative) but treated empirically like malaria.

2.5. Diagnosis. The diagnosis and confirmation of species of $P$. falciparum and $P$. vivax malaria were established by thick and thin film of peripheral blood smear examination under oil immersion with Giemsa stain and RDT. The RDTs were based on detection of specific Plasmodium spp. lactate dehydrogenase and histidine-rich protein 2.

Categorization in severe and nonsevere malaria was done on the basis of WHO guidelines for severe malaria.

\subsubsection{Initial World Health Organization Criteria from 1990}

(i) Cerebral malaria: unarousable coma nonattributable to any other cause, with a Glasgow Coma Scale score $\leq 9$. Coma should persist for at least $30 \mathrm{~min}$ after generalized convulsions.

(ii) Severe anemia: hematocrit $<15 \%$ or hemoglobin $<50 \mathrm{~g} / \mathrm{L}$ in the presence of parasite count $>10000 / \mu \mathrm{L}$.

(iii) Renal failure: urine output $<12 \mathrm{~mL} / \mathrm{kg} / 24$ hours in children and a serum creatinine $>3.0 \mathrm{mg} / \mathrm{dL}$ despite adequate volume repletion.

(iv) Pulmonary edema and acute respiratory distress syndrome.

(v) Hypoglycemia: whole blood glucose concentration $<40 \mathrm{mg} / \mathrm{dL}$.

(vi) Circulatory collapse (algid malaria): systolic blood pressure $<70 \mathrm{mmHg}$ in patients $>5$ years of age ( $<50 \mathrm{mmHg}$ in children aged 1.5 years), with cold clammy skin or a core-skin temperature difference $>10^{\circ} \mathrm{C}$.

(vii) Abnormal bleeding and/or disseminated intravascular coagulation: spontaneous bleeding from gums, nose, and gastrointestinal tract, or laboratory evidence of disseminated intravascular coagulation.
TABLE 1: Age distribution of total cases $(N=50)$.

\begin{tabular}{lcc}
\hline Age (years) & Number & Percentage \\
\hline$<1$ & 8 & $16 \%$ \\
1 to 5 & 12 & $24 \%$ \\
6 to 12 & 30 & $60 \%$ \\
\hline Total & 50 & $100 \%$ \\
\hline
\end{tabular}

TABLE 2: Sex distribution of total cases $(N=50)$.

\begin{tabular}{lcc}
\hline Sex & Number & Percentage \\
\hline Female & 17 & $34 \%$ \\
Male & 33 & $66 \%$ \\
\hline Total & 50 & $100 \%$ \\
\hline
\end{tabular}

(viii) Repeated generalized convulsions: 3 convulsions observed within 24 hours.

(ix) Acidemia/acidosis: arterial $\mathrm{pH}<7.25$ or acidosis (plasma bicarbonate $<15 \mathrm{mmol} / \mathrm{L}$ ).

(x) Macroscopic hemoglobinuria: hemolysis not secondary to glucose-6-phosphate dehydrogenase deficiency.

\subsubsection{Added World Health Organization Criteria from 2000}

(i) Impaired consciousness: arousable mental condition.

(ii) Prostration or weakness.

(iii) Hyperparasitemia: $>5 \%$ parasitized erythrocytes or $>250,000$ parasites/ $\mu \mathrm{L}$ (in nonimmune individuals).

(iv) Hyperpyrexia: core body temperature $>40^{\circ} \mathrm{C}$.

(v) Hyperbilirubinemia: total bilirubin $>2.5 \mathrm{mg} / \mathrm{dL}$.

2.6. Data Collection and Analysis. Data regarding patient age, sex, clinical presentation, investigations, and outcome were recorded. Patients were categorized in severe and nonsevere group based on WHO guidelines for classification of severe malaria. Chi square test was performed to test statistical significance of sex distribution in different age buckets. Prevalence of symptoms, signs, severity criteria, lab parameters, and their relation to mortality were studied.

2.7. Treatment. Patients were treated according to $\mathrm{WHO}$ guidelines for malaria treatment.

\section{Results}

3.1. Age Distribution of Cases. In this study most of cases were in the 6-12-year age group (see Table 1).

\subsection{Sex Distribution of Cases. See Table 2.}

3.3. Age and Sex Distribution. Overall male to female ratio was $1.94: 1$. Male to female ratio was $1: 1$ in $<1$-year age group; males outnumbered female cases in the age group from 6 to 12 years $($ male $:$ female $=5: 1)$ (see Table 3$)$. 
TABLE 3: Age and sex distribution of total cases $(N=50)$.

\begin{tabular}{|c|c|c|c|c|c|}
\hline \multirow{2}{*}{$\begin{array}{l}\begin{array}{l}\text { Age } \\
\text { (years) }\end{array} \\
\text { (year }\end{array}$} & & \multicolumn{2}{|c|}{ Sex } & \multirow{2}{*}{ Total } & \multirow{2}{*}{$\begin{array}{c}P \text { value } \\
\text { (Chi square test) }\end{array}$} \\
\hline & & Female & Male & & \\
\hline \multirow{2}{*}{$<1^{*}$} & Number & 4 & 4 & 8 & \multirow{4}{*}{0.37} \\
\hline & $\%$ & $50.0 \%$ & $50.0 \%$ & $100.0 \%$ & \\
\hline \multirow{2}{*}{1 to $5^{*}$} & Number & 8 & 4 & 12 & \\
\hline & $\%$ & $66.7 \%$ & $33.3 \%$ & $100.0 \%$ & \\
\hline \multirow{2}{*}{6 to 12} & Number & 5 & 25 & 30 & \multirow{2}{*}{0.0002} \\
\hline & $\%$ & $16.7 \%$ & $83.3 \%$ & $100.0 \%$ & \\
\hline \multirow{2}{*}{ Total } & Number & 17 & 33 & 50 & \multirow{2}{*}{0.023} \\
\hline & $\%$ & $34.0 \%$ & $66.0 \%$ & $100.0 \%$ & \\
\hline
\end{tabular}

${ }^{*}<1$ year and 1 year to 5 years of age groups have been combined for Chi square test.

\subsection{Clinical Features. See Table 4.}

\subsection{Distribution of Organomegaly. See Table 5.}

3.6. Severe Disease. WHO has defined severity parameters for malaria, which were tested for our study in terms of their frequency and their association to the outcome in the form of mortality. 13 cases (26\%) satisfied one or more criteria of WHO severity parameters and were classified as severe malaria. Clinical and laboratory profile of these cases are presented in Table 6.

\subsection{Laboratory Parameters Not Included in WHO Criteria} among Severe Malaria Cases and Outcome. See Table 7.

3.8. Outcome. Among the total of 50 cases studied 2 cases died with a case fatality rate of $4 \%$.

Among the total of 50 cases studied 10 cases (20\%) required ICU admission.

\section{Discussion}

Males were more affected than females, which is possibly due to increased outdoor activity and increased exposure to mosquitoes in males as compared to females. Kochar et al. found similar results in their study with $33.0 \%$ females affected among cases of $P$. vivax malaria. Age distribution among various age groups was $33.9 \%$ in $0-5$ years, $30.1 \%$ in $5-$ 10 years, and $30 \%$ in $>10$ years, which was almost similar in all age groups [6]. A study done in East Delhi studied population of 1 to 12 years which shows $59.7 \%$ males and $40.3 \%$ females having $P$. vivax malaria, as compared to our study which shows $69 \%$ males and $31 \%$ females having $P$. vivax malaria in similar age group of 1 to 12 years [7].

The most common presentation was fever, present in 48 out of total of 50 cases (96\%).

High fever trends are evident in $P$. vivax disease even with lower parasitemia due to its recognized lower fever-threshold (around 100 infected RBCs/microliter) [8].

It was followed by pallor which was present in 31 cases (62\%). Two common causes of anemia are increased hemolysis and decreased rate of erythrocyte production from bone
TABLE 4: Distribution of presentations in total cases $(N=50)$.

\begin{tabular}{|c|c|c|}
\hline Features & $\begin{array}{c}\text { Number of } \\
\text { cases }\end{array}$ & Percentage \\
\hline \multicolumn{3}{|l|}{ General } \\
\hline Fever & 48 & $96.0 \%$ \\
\hline Pallor & 31 & $62.0 \%$ \\
\hline Edema & 4 & $8.0 \%$ \\
\hline Body ache & 1 & $2.0 \%$ \\
\hline Respiratory symptoms & 18 & $36.0 \%$ \\
\hline Cough & 13 & $26.0 \%$ \\
\hline Tachypnea & 5 & $10.0 \%$ \\
\hline Gastrointestinal & 38 & $76.0 \%$ \\
\hline Vomiting & 24 & $48.0 \%$ \\
\hline Abdominal pain & 7 & $14.0 \%$ \\
\hline Loose motions & 4 & $8.0 \%$ \\
\hline Abdominal distension & 2 & $4.0 \%$ \\
\hline Anorexia & 1 & $2.0 \%$ \\
\hline Jaundice & 0 & $0.0 \%$ \\
\hline Bleeding & 5 & $10.0 \%$ \\
\hline Bleeding (skin and mucocutaneous) & 2 & $4.0 \%$ \\
\hline Pulmonary bleeding with hematemesis & 1 & $2.0 \%$ \\
\hline Pulmonary hemorrhage & 1 & $2.0 \%$ \\
\hline Hematuria & 1 & $2.0 \%$ \\
\hline Central nervous system & 18 & $36.0 \%$ \\
\hline Headache & 9 & $18.0 \%$ \\
\hline Convulsions & 4 & $8.0 \%$ \\
\hline Altered sensorium & 4 & $8.0 \%$ \\
\hline Diplopia and dizziness & 1 & $2.0 \%$ \\
\hline Hypotonia & 1 & $2.0 \%$ \\
\hline Signs of raised intracranial tension & 1 & $2.0 \%$ \\
\hline Squint & 1 & $2.0 \%$ \\
\hline \multicolumn{3}{|l|}{ Imaging (chest X-ray, USG) } \\
\hline Cardiomegaly & 2 & $4.0 \%$ \\
\hline Pleural effusion & 2 & $4.0 \%$ \\
\hline Pulmonary hemorrhage & 1 & $2.0 \%$ \\
\hline Pulmonary edema & 1 & $2.0 \%$ \\
\hline Ascites & 1 & $2.0 \%$ \\
\hline
\end{tabular}

TABLE 5: Distribution of organomegaly among total cases $(N=50)$.

\begin{tabular}{lcc}
\hline Organomegaly & Number & Percentage (\%) \\
\hline Hepatomegaly & 5 & $10.0 \%$ \\
Splenomegaly & 5 & $10.0 \%$ \\
Hepatosplenomegaly & 25 & $50.0 \%$ \\
No hepatosplenomegaly & 15 & $30.0 \%$ \\
\hline Total & 50 & $100.0 \%$
\end{tabular}

marrow whereas the malnutrition and intestinal parasitic infections aggravate this problem in highly endemic areas. In a study about $50 \%$ of patients with $P$. falciparum and mixed 
TABLE 6: Distribution of WHO severity parameters and outcome.

\begin{tabular}{|c|c|c|c|c|}
\hline WHO criteria for severe malaria & $\begin{array}{c}\text { Number of } \\
\text { patients with } \\
\text { severe malaria }\end{array}$ & $\begin{array}{c}\text { Percentage of } \\
\text { severe } \\
\text { malaria cases }(\%) \\
(N=13)\end{array}$ & $\begin{array}{l}\text { Number of } \\
\text { cases } \\
\text { that expired }\end{array}$ & $\begin{array}{c}\text { Percentage of } \\
\text { patients that died } \\
(\%)\end{array}$ \\
\hline Severe anemia $\mathrm{Hb}<5 \mathrm{mg} / \mathrm{dL} / \mathrm{PCV}<15 \%$ & 3 & 23.0 & 0 & 0 \\
\hline $\begin{array}{l}\text { Raised serum creatinine }(>3.0 \mathrm{mg} / \mathrm{dL}) / \\
\text { Urine output }<12 \mathrm{~mL} / \mathrm{kg} / 24 \text { hours }\end{array}$ & 0 & 0 & 0 & 0 \\
\hline Pulmonary edema/ARDS & 2 & 15.4 & 2 & 100.0 \\
\hline Abnormal bleeding & 5 & 36.5 & 2 & 40.0 \\
\hline Hypoglycemia (<40 mg/dL) & 0 & 0 & 0 & 0 \\
\hline $\begin{array}{l}\text { Repeated generalized } \\
\text { convulsions ( } \geq 3 \text { in } 24 \mathrm{hrs} \text { ) }\end{array}$ & 1 & 7.7 & 0 & 0 \\
\hline Circulatory collapse & 2 & 15.4 & 0 & 0 \\
\hline Hyperparasitemia $>5 \%$ & 0 & 0 & 0 & 0 \\
\hline Serum bilirubin $>2.5 \mathrm{mg} / \mathrm{dL}$ & 0 & 0 & 0 & 0 \\
\hline $\begin{array}{l}\text { Impaired consciousness/Glasgow Coma } \\
\text { Scale }<9\end{array}$ & 4 & 30.8 & 1 & 25.0 \\
\hline
\end{tabular}

infections were anemic while $29 \%$ of $P$. vivax infected cases had this abnormality [9].

Major confounding factors in the global analysis of anemia are the local contributors to this hematological complication such as iron-deficiency anemia [10].

None of the cases presented with renal impairment, hypoglycemia, jaundice, and hyperparasitemia.

The new WHO guidelines already point to hyperbilirubinemia (total bilirubin $>3.0 \mathrm{mg} / \mathrm{dL}$ ) as a weak marker of severity, unless it is followed by any other vital organ dysfunction [11].

Two cases died; both had pulmonary edema and bleeding and 1 case had impaired consciousness.

Major predictor of mortality among these predefined WHO severity criteria was pulmonary edema/ARDS with $100 \%$ mortality, whereas patients with severe anemia, circulatory collapse, and repeated generalized convulsions had $100 \%$ survival rate.

The statistical significance was not applicable as there were only 2 deaths among the study group.

Anstey et al. suggested that $P$. vivax patients are more likely to suffer from respiratory distress syndrome as they have more severe alveolar capillary dysfunction. Sequestration of $P$. vivax infected erythrocytes in the pulmonary microvasculature and greater inflammatory response to a given parasitic burden in $P$. vivax are probably responsible for this alveolar capillary dysfunction. Small airway obstruction, gas exchange alteration, increased phagocytic activity, and accumulation of pulmonary monocytes are the other suggested mechanisms for respiratory complications [12].

Case fatality rate in this study was $4 \%$. Most of the earlier published literature consists of few death reports or small descriptive clinical series lacking denominators. Recent study from Papua, Indonesia, reported $1.6 \%$ and $2.2 \%$ case fatality rate caused by $P$. vivax and $P$. falciparum, respectively [6]. Case fatality rate in the studies above and this study thus stresses $P$. vivax infection to be almost equally serious in causing significant mortality in comparison to $P$. falciparum.

Among the laboratory parameters as mentioned in Table 7 major predictor of mortality emerged as leukopenia with $40 \%$ mortality followed by thrombocytopenia (platelet count $<50,000 / \mathrm{mm}^{3}$ ).

Among the total of 50 cases studied 10 cases (20\%) required ICU admission.

In a study done in Manaus a rough estimation of the risk of ICU admission per species showed similar relative risks for $P$. vivax (4.7/10,000 cases) and $P$. falciparum (5.5/10,000 cases). The study included all reported cases of malaria in children of 0-14 years of age in Manaus [13].

Our study population was not an ideal population representative and that may be the reason for high ICU admission rate in our study. Further study is needed to study the burden of $P$. vivax malaria on ICU facility in hospitalized patients so as to estimate the optimum requirement of facilities to maximize the patient care.

Limitations of our study were small sample size and existing confounding factors of different parameters, though the study shows the diverse clinical presentations of $P$. vivax malaria ranging from fever to cerebral malaria, ARDS, and pulmonary edema and also emphasizes the importance of severity of $P$. vivax malaria and there is a need for further studies to establish mortality and severity predictors specific to $P$. vivax malaria.

\section{Conclusion}

The present study highlights the epidemiology of $P$. vivax malaria in pediatric age group. Since $P$. vivax was considered a benign disease, there are scarce reports. The study stresses that Plasmodium vivax can result in severe disease and can no longer be considered a benign condition. The present study shows that some manifestations of WHO severity criteria were not seen in severe $P$. vivax malaria (renal 
TABLE 7: Distribution of laboratory parameters not included in WHO criteria among severe malaria cases and outcome.

\begin{tabular}{|c|c|c|c|c|c|c|}
\hline \multirow{2}{*}{ Sample number } & \multirow{2}{*}{ Parameter } & \multirow{2}{*}{ Range } & \multirow{2}{*}{ Total number } & \multirow{2}{*}{$\begin{array}{c}\text { Percentage of total } \\
\text { cases } \\
(N=50)\end{array}$} & \multicolumn{2}{|c|}{ Died } \\
\hline & & & & & Number & $\%$ of cases \\
\hline \multirow{3}{*}{1} & \multirow{3}{*}{$\begin{array}{l}\text { Total leucocyte } \\
\text { count }\end{array}$} & Leukocytosis $\left(>10000 / \mathrm{mm}^{3}\right)$ & 5 & $10.0 \%$ & 0 & - \\
\hline & & Leukopenia $\left(<4000 / \mathrm{mm}^{3}\right)$ & 5 & $10.0 \%$ & 2 & $40.0 \%$ \\
\hline & & $\begin{array}{l}\text { Normal } \\
\left(4000-10000 / \mathrm{mm}^{3}\right)\end{array}$ & 40 & $80.0 \%$ & 0 & - \\
\hline \multirow{4}{*}{2} & \multirow{4}{*}{$\begin{array}{l}\text { Platelet counts } \\
\text { (thousand } / \mathrm{mm}^{3} \text { ) }\end{array}$} & $>150$ & 3 & $6.0 \%$ & 0 & - \\
\hline & & 100 to 150 & 10 & $20.0 \%$ & 0 & - \\
\hline & & 50 to 100 & 24 & $48.0 \%$ & 0 & - \\
\hline & & $<50$ & 13 & $26.0 \%$ & 2 & $15.4 \%$ \\
\hline \multirow{2}{*}{3} & \multirow{2}{*}{ Peripheral smear } & Positive & 49 & $98.0 \%$ & 2 & $4.1 \%$ \\
\hline & & Negative & 1 & $2.0 \%$ & 0 & - \\
\hline \multirow{2}{*}{4} & \multirow{2}{*}{ Parasitic index } & $\leq 1 \%$ & 45 & $90.0 \%$ & 2 & $4.5 \%$ \\
\hline & & $>1 \%$ & 5 & $10.0 \%$ & 0 & - \\
\hline \multirow{2}{*}{5} & \multirow{2}{*}{ RMAT } & Positive & 9 & $18.0 \%$ & 0 & - \\
\hline & & Negative & 41 & $82.0 \%$ & 2 & $4.9 \%$ \\
\hline \multirow{2}{*}{6} & \multirow{2}{*}{ SGOT } & Raised $^{\#}$ & 6 & $12.0 \%$ & 0 & - \\
\hline & & Normal & 44 & $88.0 \%$ & 2 & $4.6 \%$ \\
\hline \multirow{2}{*}{7} & \multirow{2}{*}{ SGPT } & Raised $^{\#}$ & 4 & $8.0 \%$ & 0 & - \\
\hline & & Normal & 46 & $92.0 \%$ & 2 & $4.4 \%$ \\
\hline \multirow{2}{*}{8} & \multirow{2}{*}{ Serum bilirubin } & Raised $^{\#}$ & 1 & $2.0 \%$ & 0 & - \\
\hline & & Normal & 49 & $98.0 \%$ & 2 & $4.1 \%$ \\
\hline \multirow[t]{2}{*}{9} & \multirow[t]{2}{*}{ Serum creatinine } & $\begin{array}{l}\text { Raised } \\
(>1.0 \mathrm{mg} / \mathrm{dL})\end{array}$ & 5 & $10.0 \%$ & 1 & $20.0 \%$ \\
\hline & & $<1.0 \mathrm{mg} / \mathrm{dL}$ & 45 & $90.0 \%$ & 1 & $2.2 \%$ \\
\hline
\end{tabular}

${ }^{\#}$ Based on normal reference range for age and sex.

impairment, hypoglycemia, jaundice, and hyperparasitemia), whereas leukopenia and thrombocytopenia which are not part of WHO severity criteria were frequently present and were associated with mortality. This implicates the need for separate severity parameters for $P$. vivax malaria. However, larger studies need to be undertaken to establish the specific severity parameters and poor prognostic indicators.

\section{Conflict of Interests}

The authors declare that they have no conflict of interests.

\section{References}

[1] WHO, World Malaria Report 2013, World Health Organization, Geneva, Switzerland, 2013.

[2] D. K. Kochar, V. Saxena, N. Singh, S. K. Kochar, S. V. Kumar, and A. Das, "Plasmodium vivax malaria," Emerging Infectious Diseases, vol. 11, no. 1, pp. 132-134, 2005.

[3] D. K. Kochar, A. Das, S. K. Kochar et al., "Severe Plasmodium vivax malaria: a report on serial cases from Bikaner in northwestern India," American Journal of Tropical Medicine and Hygiene, vol. 80, no. 2, pp. 194-198, 2009.

[4] B. Sina, "Focus on Plasmodium vivax," Trends in Parasitology, vol. 18, no. 7, pp. 287-289, 2002.
[5] S. Picot, "Is Plasmodium vivax still a paradigm for uncomplicated malaria?" Medecine et Maladies Infectieuses, vol. 36, no. 8, pp. 406-413, 2006.

[6] D. K. Kochar, G. S. Tanwar, P. C. Khatri et al., "Clinical features of children hospitalized with malaria-a study from Bikaner, Northwest India," The American Journal of Tropical Medicine and Hygiene, vol. 83, no. 5, pp. 981-989, 2010.

[7] S. Gomber and L. Kabilan, "Prevalence of malaria in East Delhi-a hospital based study," Indian Pediatrics, vol. 36, no. 6, pp. 579-580, 1999.

[8] P. A. Zimmerman, R. K. Mehlotra, L. J. Kasehagen, and J. W. Kazura, "Why do we need to know more about mixed Plasmodium species infections in humans?" Trends in Parasitology, vol. 20, no. 9, pp. 440-447, 2004.

[9] N. Latif, M. S. Ejaz, S. Hanif, and H. Memon, "Clinical and hematological pattern in patients with Plasmodium vivax," Medical Channel, vol. 18, no. 1, pp. 48-51, 2012.

[10] M. V. G. Lacerda, M. P. Mourão, M. A. A. Alexandre et al., "Understanding the clinical spectrum of complicated Plasmodium vivax malaria: a systematic review on the contributions of the Brazilian literature," Malaria Journal, vol. 11, article 12, 2012.

[11] World Health Organization, WHO Guidelines for the Treatment of Malaria, World Health Organization, Geneva, Switzerland, 2nd edition, 2010.

[12] N. M. Anstey, T. Handojo, M. C. F. Pain et al., "Lung injury in vivax malaria: pathophysiological evidence for pulmonary 
vascular sequestration and posttreatment alveolar-capillary inflammation," The Journal of Infectious Diseases, vol. 195, no. 4, pp. 589-596, 2007.

[13] E. F. C. Lança, B. M. L. Magalhães, S. Vitor-Silva et al., "Risk factors and characterization of plasmodium vivax-associated admissions to pediatric intensive care units in the brazilian amazon," PLoS ONE, vol. 7, no. 4, Article ID e35406, 2012. 


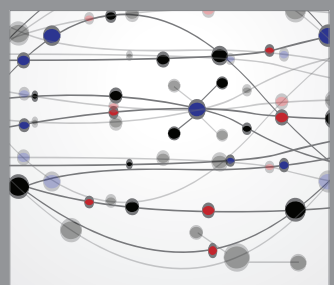

The Scientific World Journal
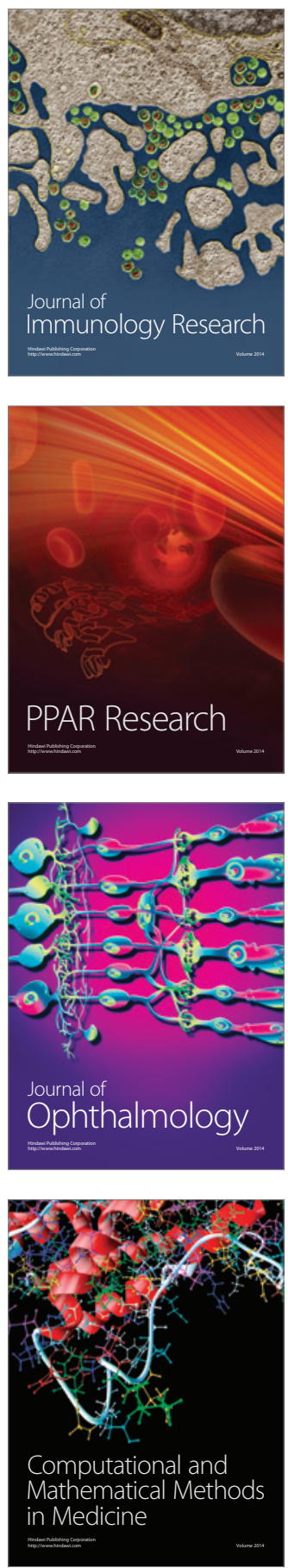

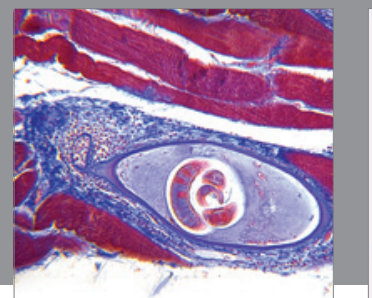

Gastroenterology

Research and Practice
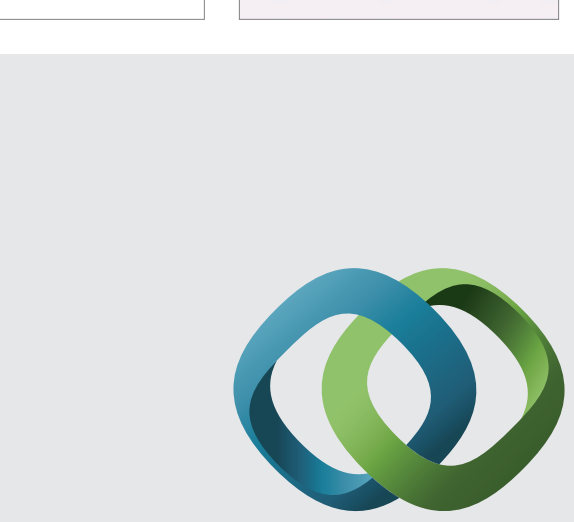

\section{Hindawi}

Submit your manuscripts at

http://www.hindawi.com
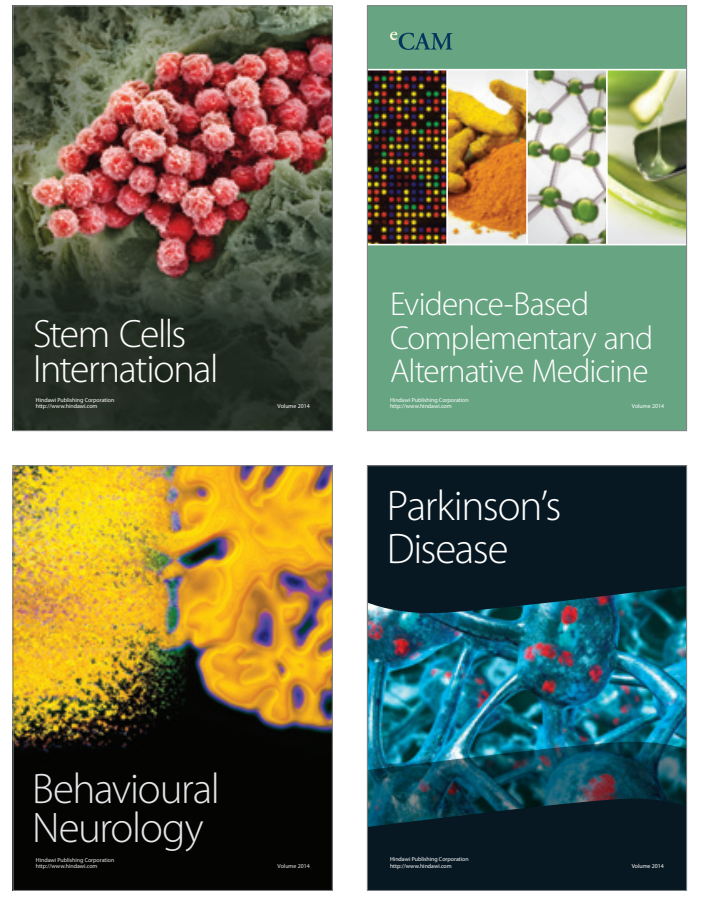
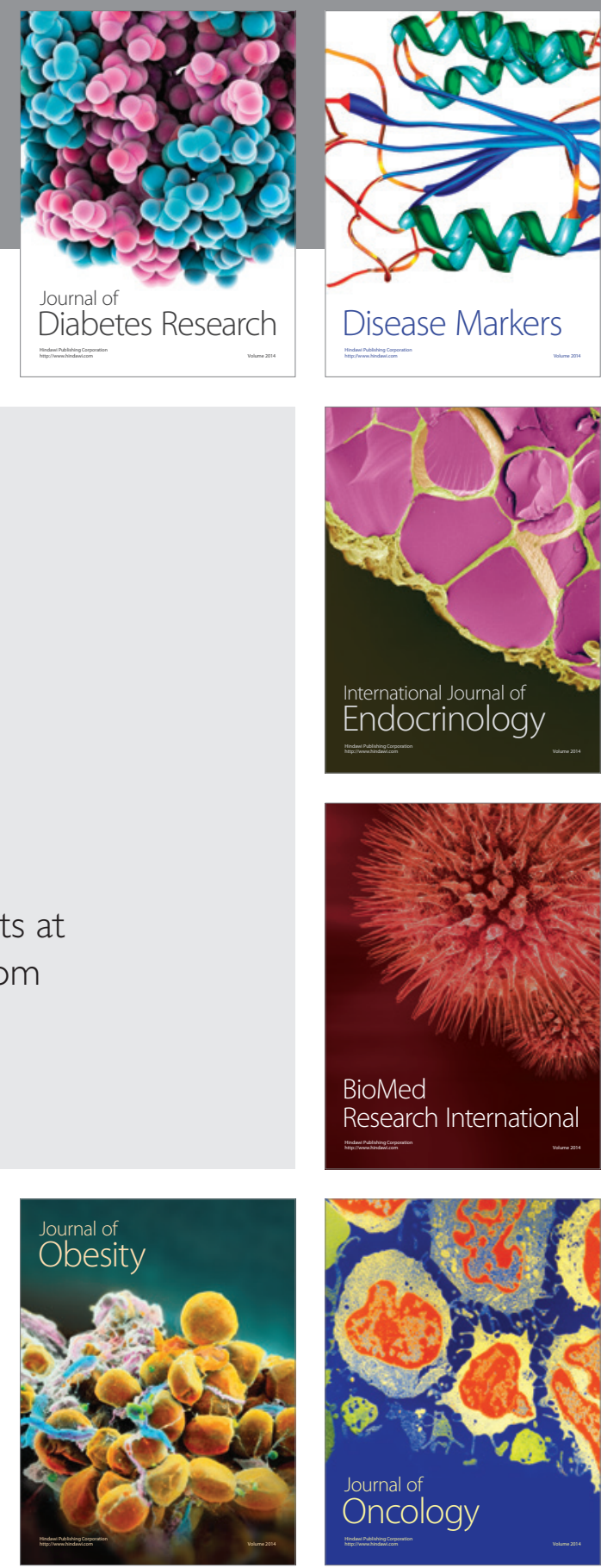

Disease Markers
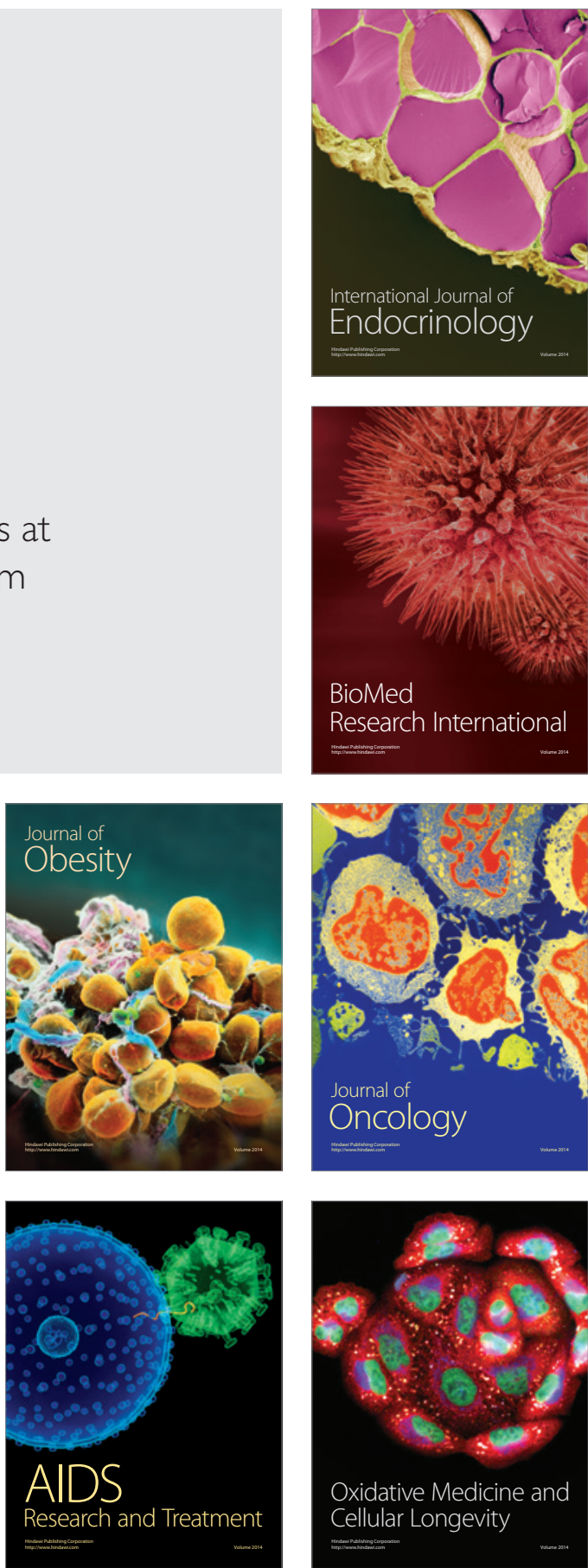